\title{
The Accessible Tourism in Lisbon, as a Challenge for the "Art" of Tourist Guiding
}

\author{
Ilídia Carvalho ${ }^{1,2}$ \\ ${ }^{1} \mathrm{PhD}$ in Accessible Tourism, Lisbon University, IGOT, Lisbon, Portugal \\ ${ }^{2}$ Official Tour Guide and Teacher, Lusíada University, Lisbon, Portugal
}

Copyright $\subseteq 2018$ by authors, all rights reserved. Authors agree that this article remains permanently open access under the terms of the Creative Commons Attribution License 4.0 International License

\begin{abstract}
People with special needs are travelling all over the world, thanks to the last developments at technological level and mainly because of the changing of mentalities about impairment. Tourism destinations have to be prepared to receive this new kind of tourism and the required adaptations must concern the physical barriers and the human barriers as well. Tourism professionals in general should be informed and trained to deal with the human diversity. Tourist guides are some of the most important professionals on dealing with accessible tourism and their performance can be of extreme importance for the success of a travel experience. To be able to guide a group when there is someone travelling in a wheelchair, can be a challenge and requires some sensitivity and knowledge, not only about special needs of the visitors but also about the real accessibility conditions of the places. Based on the professional experience of the author and a mixed method research using questionnaires, interviews to tourists and day visitors as well as the results of a focus group with tour guides, this paper intends to give some answers about what visitors in a wheelchair expect from a tour guide and how these are supposed to behave in such a situation. The findings show how accessibility is a fundamental concept in tourism and the important role a tour guide can play.
\end{abstract}

Keywords Accessibility, Tourism Destinations, Human Barriers, Tour Guiding, Accessible Tourism

\section{Introduction}

We are aware that more studies about tourist guiding and the challenge that can be for these professionals to guide people with disabilities are necessary, because tourism is one of the most important social economic activities all over the world. Tourism has being presented as a dream way to solve many problems and it is true that it has become a necessity for the human welfare and involves many different and interesting aspects. Nowadays we have a new type of tourism being the client more individualist and demanding and the supply is now trying to answer to all different kind of interests and needs.

The interest about these new kinds of tourism is increasing and the case of adapted tourism for people with disabilities, the so called accessible tourism, is not an exception. Several interesting studies about accessible tourism in Europe have been made. Authors like Darcy \& Buhalis [1-2] wrote about many fundamental aspects of this kind of tourism, Bi, Card \& Cole [3] tell us how it is increasing in China and Yau, Mckercher \& Packer [4] give us an focused perspective of how it is to travel with a disability. Also Devile [5-6] has presented studies about accessible tourism in Portugal, where this study was carried on. But until now not so many wrote about how the tourism guides should handle this type of visitors.

This article aims to provide more information about the relationship between guides and accessible tourism so that it will be possible for guides to answer in a better way to the interests and needs of the visitors with disabilities. Nevertheless before we start explaining our study we think it is important to explain shortly what accessible tourism is.

\section{Accessible Tourism}

Accessible tourism (AT) has different definitions according to different authors and perspectives. Some of them have studied AT from a more economical perspective like we find on the FMET report [7], others such as Gonzalez \& Alonso [8] have written with more social concerns. Some of them have presented more the supply issues and only a few have looked properly at the AT from the side of demand. Like Darcy \& Buhalis [1] say: "accessible tourism ... as been described most commonly through an estimation of the market size or an estimation of the economic contribution of the group [which] does little to assist in understanding the complexity of the market segment".

With an ever growing interest in this activity, there has 
been an enormous development through these last decades concerning the concept of AT, but this paper will consider the following one:

Accessible tourism is a form of tourism
that involves collaborative processes
between stakeholders in order to offer
universally designed products, services
and environments to be able to eliminate
physical, human or information barriers,
enabling people with special access
requirements, including mobility,
vision, hearing and cognitive dimensions
of access, and their companions, to
practise tourism with equity and dignity
looking always for the maximum
independence.

Source: the author (adapted from several authors)

This development and interest about AT has to do mainly with the new mentality about impairment and disability, since we have left the medical concept behind to embrace a social concept that allows facing people with disability in a different way. The social model views disability as having a social dimension and regards impairment as a part of the human diversity as referred by Darcy \& Buhalis [2].

In 1948 when the UN Convention of the Human Rights was signed, we started a long way that has brought us until this moment when people with disability are considered to have exactly the same rights as all the others, including the right to travel and enjoy all different touristic activities.

But even though AT has always been connected to visitors with disability nowadays we consider that, thanks to human diversity, many other persons do fit in this category, and we should say that this will suit all visitors with an special access need.

In order to be sure that the environment will provide the needs of all these visitors the Universal Design has to be implemented to all products, services and environments from the up to the downstream of the touristic chain so that the experience will be positive because as Prescott [10] refers, accessible tourism must be seamless.

According to one of the most recent studies about Economic Impact and Travel Patterns of Accessible Tourism in Europe, which was presented by the EC -European Commission [9]: The demand for accessible tourism will also continue to grow in future, with the forecast of future growth suggesting that by 2020 the demand by people within the EU will grow to about 862 million trips per year whilst the demand by the key international inbound markets will reach 21 million trips per year, and possibly more if accessibility improves in the tourism sector.

This is a reality that tourism destinations cannot fail to consider and according to Eichhorn \& Buhalis [11] we find 3 types of barriers - physical, human and information - and all them have to be eliminated so that a tourism destination will be able to be considered as an accessible one.

But, if physical barriers and even some information ones are easy to identify, the same doesn't apply to human barriers. How can we eliminate them? It is mainly a question of awareness and sensitiveness.

\section{Tour Guiding: Information or Human Barrier?}

Tour guiding may be considered as an "art" because a guide must adapt to the visitor and each visit is different because we are dealing with human beings. Depending on the gender, age, nationality, cultural level and special needs of those that have purchased the tour guide service, this professional must adapt the information given and must be able to transmit the knowledge in a way the visitor can understand. Not only the capability of speaking fluently the language of the visitor is needed but also to be able to know the cultural references of the visitor and understand the special needs of each one of them. All this allow a good performance which will result on the success of the visit.

Since our aim is to study tourist guiding and accessible tourism, this could be at the first glimpse easily related in some aspects to the information barriers, because a guide is a privileged communicator giving information about several items concerning the country being visited. When dealing with deaf visitors it would be good to know gestural language to overcome a certain information barrier. When dealing with blind people a tour guide should have the sensitiveness to avoid expressions like: As you can see on your right... and should try to explain things in a more detailed way. In this particularly case, the guide should also try to make possible for them to touch things being explained ${ }^{1}$ because tour guiding is much more than giving information it is to adapt to the needs of the visitor. The relationship between tour guide and visitor is so rich and complex that this activity must be mainly related to the human barriers.

In the above mentioned study of the EC [9] it is said that overall attitudinal barriers are encountered more often than physical access barriers. Also Bi et al. [3], when referring to Schleien et al., 1997 and Smith et al., 2001, say that human or "attitudinal barriers were the most limiting barriers encountered by individuals with disabilities, and

1 In many museums and monuments they already allow these visitors to touch the objects. The museums have developed strategies to adapt to the accessible tourism, like the coach museum in Lisbon where we find a small model of a coach for them to touch. But unfortunately they have no signs in Braille. 
the hardest to overcome".

This kind of barrier is not only difficult to identify but is also very difficult to eliminate because it takes a long time until the collective and personal mentality changes and sometimes there is a gap between what we really think and what we know that we are supposed to do. People in general need to be prepared to deal with accessible tourism and the professionals like tour guides need to be skilled to be able to receive these visitors and give the right answer towards their special needs.

After the family and friends that are usually the companions of the visitors with disability, they do rely on the tour guides when they are travelling, as Yau et al. [4] have noticed on their study about Chinese travellers with physical disabilities: If relatives or friends are not available, participants felt they must rely on busy tour guides.

Notice that they refer to busy tour guides. This calls our attention for the fact that the guide has several things to do at the same time and usually must pay attention to several tourists simultaneously which can easily result in an attitudinal barrier.

When people with disability are travelling as individual and hires the private service of a tour guide this will be an easier task for this professional, because the guide can focus only on this special visitor which allows this professional to go towards the special needs presented. But when dealing with a group, the task get harder because depending on the limitations presented by some of the visitors it is sometimes necessary to discretely adapt the tour and at the same time to be able to keep a good atmosphere in the group.

When travelling with a group we also must distinguish two different situations:

1) Closed group - when people know each other and they also take care of the special needs of the person or at least they accept/understand the adaptations that are possible to occur during the visits.

2) Open Group - people don't know each other before and the group can also sometimes turn to be a huge barrier depending on the sensitiveness of the participants and the degree of disability.

In accessible tourism, this tour guiding "art" can be sometimes more complicated because it has not only to do with the guide as a person but also with many other aspects that are not depending on this professional, being this professional mostly the "bridge" between visitor and services or environment that sometimes are not properly adapted. The tour guide, when skilled, may help to avoid or at least minimize some of the barriers that the visitors with disabilities may find.

\section{Methodology}

This paper adopts an exploratory research model to understand relationship between tour guiding and people with disabilities. Because it results from a much larger study which has been carried by the author about AT in Lisbon, it will only consider visitors with physical disabilities, namely those going around in a wheelchair. By the same reason it will only analyse the situation of accessible tourism in this town.

It presents a mixed method research consisting on quantitative data obtained through questionnaires and qualitative data coming from interviews and the results of a focus group. This method is considered by Bryman [12] to give us a better comprehension of a phenomenon than by using a single method. This method makes possible to have complementary information and different perspectives about the subject, allowing the investigator to have a better knowledge about the total phenomenon. But it also demands more work from an investigator to keep the distance needed to be able to guarantee the validity and reliability of the data obtained.

The questionnaires that had both quantitative and qualitative questions were applied from March 2012 to July 2013. This questionnaire focused on tourists was delivered to them when arriving in their wheelchair at one of the 10 hotels that have participated in this study. It had 34 questions divided in 3 parts: Characterization of the population, Travel Habits and Motivations, finally Behaviour and Considerations about Lisbon. For this paper only some questions (4) will be considered since only those are directly related to tour guiding and the evaluation of tourism professionals to handle with visitors with disabilities. In total, 48 valid questionnaires were obtained ${ }^{2}$ which allowed having the opinion of tourists about Lisbon as an accessible town.

The semi-structured interviews were held throughout the year 2012 and took place during a visit in Lisbon guided by the investigator herself. They were applied to tourists (4) and day visitors (6). In this last case they all arrived to this town on a cruise ship. Seeking cover several possibilities, we tried to consider visitors of different ages, gender and using both manual and motorised wheelchairs. It allowed to obtain different information about accessibility in Lisbon.

To be able to examine both the perspectives from demand and supply we have organised a focus group ${ }^{3}$, which took place in December 2012, participating 8 tour guides of both sex and several ages, which were used to work with several nationalities and covering several generations of professionals. The result was very rich in issues about the relationship between these professionals

2 Even though it is not a big amount of questionnaires for classic quantitative studies, there are nowadays several authors considering 30 questionnaires as the minimum valid number.

3 This focus group was the way found by the investigator to be able to distance herself from the colleagues of profession, being able to get some more reliable information, which by using the simple interview, could be compromised. 
and the visitors with disabilities focusing mainly those in a wheelchair.

The already existing professional experience of the investigator consisting on direct observation, together with the analyses of all the results of this study, made possible to deep our knowledge about the interactions between these tourism professionals and people with disabilities.

\section{Study Presentation}

\section{A) Questionnaires}

The investigator intended to know which were the human barriers in Lisbon and when the 48 tourists were inquired about the Lisbon population in general as being prepared to deal with visitors in a wheelchair, the majority with $68,8 \%$, said that they considered the population to be prepared. There was also a small percentage of tourists who said they didn't know, maybe because they did not have much contact with the population. This happens sometimes when they are travelling with a group.

But in this study was intended to know mainly their opinion about the tourism professional in Lisbon, like receptionists, bus tourism drivers and guides and several questions were then asked by the investigator who obtained the following results:

Table 1. Question 1 - Are tourism professionals prepared to deal with visitors with disabilities?

\begin{tabular}{|c|c|c|}
\hline $\begin{array}{c}\text { Tourism Professionals } \\
\text { (in general) }\end{array}$ & Preparation & $\%$ \\
\hline Yes & 24 & 50 \\
\hline No & 11 & 22,9 \\
\hline Do not know & 1 & 21 \\
\hline No answer & 12 & 25 \\
\hline Total & 48 & 100 \\
\hline
\end{tabular}

As presented above the answers were very positive with $50 \%$ of the tourists saying that in general these professionals were prepared to receive this kind of visitors.

Table 2. Question 1a - Are hotel receptionists prepared to deal with visitors with disabilities?

\begin{tabular}{|c|c|c|}
\hline Hotel receptionists & Preparation & $\%$ \\
\hline Yes & 38 & 79,2 \\
\hline No & 4 & 8,3 \\
\hline Do not know & 1 & 2,1 \\
\hline No answer & 5 & 10.4 \\
\hline Total & 48 & 100 \\
\hline
\end{tabular}

The hotel receptionists also had a very positive percentage $(79,2 \%)$ but concerning the bus tourism drivers and tour guides this percentage reduced respectively to $45,8 \%$ and $35,4 \%$ because many of the tourists did not use their services as it was possible to perceive by the high percentages of the item "do not know" which presented respectively $37,5 \%$ and $45,8 \%$.

That led the investigator to other following questions: Why didn't they use those services? Has it to do with the price, bad experiences or because they simply don't think it is good to use the services of a guide? So, they were asked:

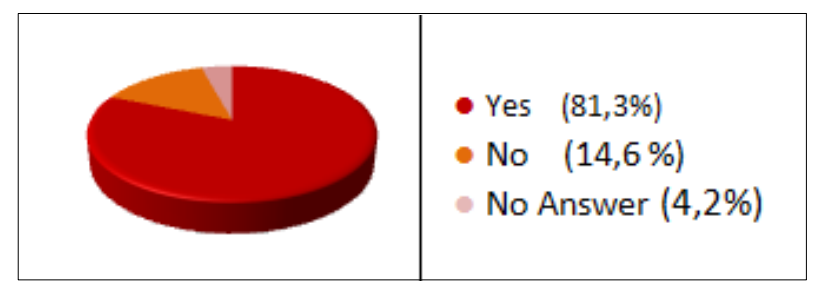

Figure 1. Question 2 - Do you think positive to use the services of a tour guide?

Even though the majority of the tourists inquired $(81,3 \%)$ considered positive to use the services of a tour guide we must not forget that only 23 of them have really used this services while they were in Lisbon.. From these, 15 were travelling with a group and 8 individually. This has probably to do with the fact that is far more common to use a guide when travelling with a group than individually. But we must consider that tourists with disabilities do prefer to travel alone, since from our 48 inquired tourists, only 14 usually travel with an organised group.

\section{Question 3: Which are the reasons to consider positive or negative the tour guide service?}

To be able to understand what they exactly expect from a guide they were asked, why they think it is positive and also the reasons for a part of them to have considered it negative. By using a multiple answer question where they should choose the two most important reasons, but also having the possibility to introduce an extra item, the following results were obtained:

Table 3. Positive reasons to use a tour guide

\begin{tabular}{|c|c|c|}
\hline & Number & $\mathbf{\%}$ \\
\hline Better general information & 34 & 70,8 \\
\hline Good adaptation: way v. mobility & 14 & 29,2 \\
\hline More safety & 12 & 25,0 \\
\hline Kindness/Solidarity & 9 & 18,8 \\
\hline Maximization of time & 8 & 16,7 \\
\hline
\end{tabular}

Related to the negative aspects considered and still using a multiple question with the possibility to choose two answers and the possibility to write an extra one, we have: 
Table 4. Reasons not to use a tour guide

\begin{tabular}{|c|c|c|}
\hline & Number & $\mathbf{\%}$ \\
\hline To much or less information & 1 & 2,1 \\
\hline Price & 1 & 2,1 \\
\hline Bad information v. mobility & 1 & 2,1 \\
\hline No sensitiveness & 0 & 0,0 \\
\hline Bad timing adaption v. mobility & 0 & 0,0 \\
\hline Others (extra item)* & 4 & 8,3 \\
\hline
\end{tabular}

* prefer to plan the visit alone or to long visits or just like to be alone.

It is than possible to say that the information item in general is considered to be the most positive aspect chosen by $70,8 \%$ of the tourists which is related with the basic function of a guide (see Table 3). But this is followed by the capacity to adapt well the way to the mobility as well as the feeling of safety which is connected with others important aspects from which this visitors are depending. They are counting on the guide for sure.

The negative opinions given in Table 4 have much to do with the fact that they mostly prefer to be alone, and they prefer to decide what to visit, following the main stream of the new kind of tourism where tourists are more independent and prefer to travel individually. The price for example doesn't seem to have great importance. But there is an important aspect referred which is: to long visits and this may have to do with the programs that sometimes are not ideal for some of the visitors with mobility problems. This aspect led the investigator to other question:

\section{Question 4: Would you like to join accessible tourism tours?}

The investigator asked about the acceptance to join accessible tours which are better adapted to these visitors allowing them to avoid easily some possible existing barriers and which are already possible to find in Lisbon as in many others tourism destinations. The answers were:

25 were interested and from these, 17 were still interested even if they had to pay more for this service. The main reason given not to use these services, in general, was because they didn't know about it, what can be directly connected to the importance of the information given about accessible services which unfortunately is not the best one.

\section{B) Interviews}

To be able to know the different opinions of visitors and tourists considering that they may have different perspectives since the contact/experience they have of the existing barriers may differ a lot, the investigator has interviewed 4 tourists and 6 day visitors being 5 women and 5 men with an age between 25 and 80 years old. The majority of them travelled with companions and only one of the tourists was travelling alone.

The tourists stayed in Lisbon from 5 to 7 days, while the day visitors remained only a few hours which may of course influence their experience. Nevertheless all these visitors have made a guided tour with the investigator, during which these interviews have taken place. This guided tour was proposed by the investigator in ex-change of the information, otherwise the tour guiding service would probably not have been experienced, because none of the visitors interviewed had made the reservation for it. Nevertheless, the presence of the investigator was well accepted and one of the visitors (Kris) at the end has even said: "This was the best tour I ever made, I'm so glad that you were with us and that we were able to visit places that we never thought being possible to visit in a wheelchair. I would never manage to do it alone".

This proves how important the tour guides may be for AT and how they can influence the success of a visit when skilled and well informed. Clients tend to trust the guide. But having a guided tour can also be a bad experience like another interviewed said: "I went on a tour but I was left behind because the guide moved to quick and I remained alone with my wife" (Roger). In this case, the client counted on the guide to show him around and is disappointed when left behind because he needed some more time and attention.

When they were directly asked, what do they expected from a tour guide, they answered:

"Someone nice who understands our limitations" (Marco) or "Someone with knowledge about history and art but also who knows about the accessibility of places to be visited" (Ann) or even "I expect someone who will tell me where I should go being aware of the accessibility of those places because I don't like risks nor wasting time" (Collen).

It is possible to consider that it much depends on the sensitiveness of the guide but also the time limitation of the tour and the program presented to this professional. Connected to the tour guiding when dealing with AT, the programs have to be taken in consideration, because they are very important not only referring to the items included, which are supposed to be accessible, but also in what timing is concerned, because these persons need more time to step on and off. In AT is essential always to balance the difficulty presented by some visits with the profit that the person takes from it and most of the time the adaptation of the program turns to be a guide responsibility. Risks should also be avoided because safety is an important item to AT, nevertheless it must also be taken in consideration that these visitors also like "controlled" adventure. Which means that some of the tours usually proposed to visitors with disabilities at the mobility level are the easiest proposals for the offer and they do take mainly into account the safety aspect, but they are sometimes not the best for the demand, because as one visitor said: "To visit a town is to smell it, ear it and walk around" or as another said: "I took a tour which was only panoramic and I was not happy 
with it because I want to have more than a panoramic tour. For that experience I could have used Google earth".

Among these visitors several reasons were founded at different levels not to participate on a organised tour, which many times also means not to use a tour guide:

1) Some of them do expect more than a panoramic tour and that is why they don't participate on organised tours. They want more. The solution may consist on having several possibilities for them to choose depending on their capacities, which is directly connected to the human functionality.

2) Others had a bad experience with the tour guiding or even with the bus driver who did not help them or even with the others participants who discuss about the front seats;

3) Some others say that they don't participate on tours "because they feel they are holding the others" or "they feel like a burden". One of the strategies developed by these visitors to avoid this situation is to remain sitting on the bus while the others do the visit. In this case they don't profit from what they have purchased;

When they were asked about the possibility to join an accessible tour organised by a specialized agency in AT with adapted vehicles and someone skilled to guide them, the answer were quite surprising because only 3 interviewed said they would like to participate in such a tour. Probably the price may have something to do with it, but the truth is that only one of them referred directly to the price. Another called the attention to the fact that "maybe the companion wouldn't like to go on such a tour". This confirms the strong symbiosis between visitor and companion. Another one was afraid of what "kind" of participants this tour would have because they seemed to be afraid to get on a tour together with others that may have another type of disability like for instance the intellectual one.

\section{C) Focus Group}

The investigator intended to know the opinion of tour guides about accessible tourism and how they managed to work with visitors with disabilities. From the 8 guides participating in this focus group, we had 2 men and 8 women and their age was from 28 to 57 years old. Their professional practise went from 2 to 33 years working as a guide in Lisbon. Some of them were used to guide either private tours or groups having people in a wheelchair, while others had only had sporadically this situation when guiding some tour with a group coming from a cruise ship.

Several measures were proposed as necessary for a guide to be able to answer properly to the needs of these visitors:

\section{- Before Arrival}

1. To know in advance if there is someone participating who has special needs, which are those needs and how deep is the disability;
2. Verify the program to check the difficulties/barriers than can be found.

3. Whenever possible contact in advance all the others services to warn them about this situation, to know about the real accessibility conditions and trying to find out solutions in case there will be some barriers presented.

\section{- At the Arrival}

1. Whenever possible reserve the front seat on the bus when dealing with a group;

2. Try to understand by talking directly with the visitors and their companions which are their motivations, interests and needs;

3. Inform clearly about the critical points of the program and discuss the possibilities to overcome them.

\section{- During the Visit}

1. Wait until all visitors (including those in a wheelchair) come out of the bus before starts moving towards the touristic attraction to be visited;

2. Avoid situations where the guide has to push the wheelchair, only when is reality necessary (a part from being an increased responsibility, it doesn't allow them to pay so much attention to the others visitors);

3. A guide should not give more attention to some visitors than the others, they are all equally important;

4. Wait until all have arrived before starting the explanations and it would be better if the visitor in a wheelchair was positioned in the front.

Some items were also evaluated as important to the success of a tour and the good relationship between guide and client with special needs, like the collaboration of the bus driver, an accessible hotel and a program well adapted since the beginning, which is rare to find because until now many agencies mainly rely on the tour guide to do this adaptations.

\section{Discussion of Results}

Since Portugal is known as a country where hospitality is one of the main characteristics appealing to the visitors, we decided to study the capacity of its capital to receive those visitors in a wheelchair. In this study the results about physical barriers presented some problems with sidewalks and street crossing passages, but in what human barriers in Lisbon are concerned, the results were quite good.

A tour guide is a person who by nature should adapt to the different visitors and situations and always thinking in "the welfare of the tourists" as Brito [13] refers. This adaptation as we have seen before can be considered to be 
an "art" since it depends from so many different aspects like nationality, age and culture of the visitor. Nowadays we also have to consider the special needs because if in the past people with disabilities tended to participate only on religious and health trips, today we may find them in all different segments of market connected to the tourism activity and their number is increasing.

Considering the questionnaires and interviews, sympathy and kindness appear to be an important aspect expected from a guide when dealing with AT, as well as information given about culture and art, but also accessibility. The guide has to be able to give such information about accessibility which will allow the client to feel safe and sure to be able to maximize the visit taking into account the limitations presented.

The capability of a guide to adapt to new situations and needs when guiding a visitor or a group can influence a lot the success of a tour. That is why Brito [13] says "the success (or failure) of a trip depends on the guide..." As we referred before, it can be quite different the performance of a guide when we are dealing with an individual or a group and it is even more difficult to adapt the performance to the situation if it is an open group, where people don't know each other, resulting in even an harder task for the tour guide. We can also say that this capability depends on both the skills and sensitiveness of these professionals. But training should also been available and that's why the European Network for Accessible Tourism (ENAT) has a new project for the training of guides to be able to work with visitors with special needs. T-GUIDE ${ }^{4}$ aims to enable all visitors, regardless of an intellectual or learning difficulty, to have an enriching and meaningful tourism experience by taking part in a professionally guided tour.

The knowledge showed about the needs of visitors with disability by some of the guides who composed our focus group seems to have been acquired only from the practise. They were confronted with different situations and they were able to learn out of these difficulties, some of the best ways to behave, when dealing with this kind of visitor. But it could have been easier for both the guide and the visitor if the first one had had some preparation for it. It would have allowed skipping some failures and risks that took place in all this learning process.

It cannot be forgotten that this kind of tourism, as the study presented by EC [9] presents, is increasing and the guides will be facing this situation often and that's why they must be prepared. The professional tour guides must also be aware of the importance they may have in all this process because as Brito [13] says: they are often the "face" of a destination to the visitor, giving a personal welcome and contributing to a lasting impression of the

4 This project was presented on the $31^{\text {st }}$ of March 2014 in a conference which took place in Brussels. See more information in the site: www.t-guide.eu place, its people and its cultural significance.

But the performance of the tour guide cannot be disassociated from the program presented by the agency and many times they have a detailed program that they are obliged to follow. It is also fundamental that these programs adapt to the special needs of the visitors and the agencies must also be aware of this issue. Since this usually do not happens tour guides are obliged to solve alone these situations sometimes presenting huge difficulties for them as professionals since they have a program to follow and other persons to guide and when they change something it is by their own risk and responsibility. This is only an example of the importance of the accessibility chain presented by Ambrose [14] or the systemic view of tourism presented by Devile [5-6] where all elements are connected and are essential for the best result.

\section{Conclusions}

About accessible tourism it is possible to say, that tourism destinations are now supposed to adapt to this new reality and this adaptation has two reasons to happen: the economical one, which has always been considered, but the social one as well.

For a good and total adaptation to happens, not only physical barriers are to be eliminated but also human and information ones as Devile [6] and Yau et al. [4] referred. We must also consider that tourist guiding is specially connected to both these last barriers.

When using the services of a tour guide visitors with disability expect some sensitiveness and knowledge not only about the usual cultural information given, but also to advise them where to go and helping them to find the right answers to their special needs. This means that these professionals have to be well informed about the accessibility of the visited places. But they should also be informed in advance about the particular mobility conditions of the visitor, to be able to prepare the visit in a proper way, as Brito [13] refers, and it would certainly be much easier if the programs they receive would already consider these mobility conditions.

Lisbon tour guides still have a hard task presenting this town as an accessible tourism destination, mainly because of all the existing physical barriers which we expect will soon disappear, since the adaptation process is already on its way and much has already been done, especially at the hotel level.

In the future in what tourist guiding is concerned, to turn possible a successful visit to visitors with a disability in a better way, is essential to prepare these professionals providing them the skills by training them, instead of depending on the accumulated experiences as it has been so far done. It would be then easier for them to be able to respond to the needs of this kind of visitors which number as it was mentioned, intends to increase and which needs 
can be so widely different between persons presenting similar disabilities, all because of the human functionality that can differ so much, turning all this process more difficult but by the other hand more challenging.

The success of a visit, which certainly influences people to come back and also to advise others to come to a particular tourism destination, always depends on the way these visitors have been received and tour guides are an angular stone for this matter as the results of this study have shown.

The good touristic experience is fundamental for such a well-known tourism destination like Lisbon, to be able to maintain a good international ranking, attracting all types of visitors from all over the world and to be able at the same time to develop the social responsibility.

\section{REFERENCES}

[1] S. Darcy, D. Buhalis. Introduction: From Disabled Tourists to Accessible Tourism. In Buhalis D., Darcy C. (eds.) Accessible Tourism. Concepts and Issues. Aspects of Tourism Series. Channel View Publications, Bristol, 1-15, 2011

[2] S. Darcy, D. Buhalis. Conceptualizing Disability. In Buhalis D, Darcy C (eds.) Accessible Tourism. Concepts and Issues. Aspects of Tourism Series. Channel View Publications, Bristol, 21-42, 2011.

[3] Y. Bi, J. Card, S. Cole. Accessibility and Attitudinal Barriers Encountered by Chinese Travellers with Physical Disabilities. In International Journal of Tourism Research, vol 9, 205-216. Published on line in Wiley Interscience 2007.

[4] M. Yau, B. Mckercher, T. Packer. Traveling with a Disability. More than a Access Issue. In Annals of Tourism Research, Vol 31, n 4, 946-960, 2004.

[5] E. Devile. Dinâmicas de Envolvimento das Pessoas com Incapacidades nas Atividades Turísticas. Dissertação para obtenção grau de Doutora em Turismo. Departamento de Economia, Gestão e Engenharia Industrial. Universidade de
Aveiro. Portugal, 2014.

[6] E. Devile. O Desenvolvimento do Turismo Acessível: dos Argumentos Sociais aos Argumentos de Mercado. In Turismo Acessível. Revista Turismo e Desenvolvimento, $\mathrm{n}^{\mathrm{o}}$ 11, Aveiro, 39-46, 2009.

[7] FMET - Federal Ministry of Economics and Technology. Economic Impulses of Accessible Tourism for All. Project managers of the Study P. Neumann \& P. Reuber, Summary of Results, March 2004. Doc. 526. Berlin. 2004.

[8] A..Gonzalez, E. Alonso . Hábitos y Actitudes hacia el Turismo de las Personas com Discapacidad Física. Informe de resultados. Predif- Plataforma Representativa Estatal de Discapacitados Físicos. Secretariado Nacional de Reabilitação. España, 2004.

[9] EC -European Commission. Economic Impact and Travel Patterns of Accessible Tourism in Europe, Study carried on by GFK, University of Surrey, Neumann Consultants and Pro-Solutions. Financed by EU Preparatory Action for Tourism and Accessibility for All, 2014. [online - 22nd November 2014] ec.europa.eu/DocsRoom/documents/5566/attachments/1/.../ en/.../native

[10] M. Prescott. Universal Tourism Networks. In Buhalis D., Darcy S., Ambrose I. (eds) Best Practice in Accessible Tourism. Inclusion, Disability, Ageing population and Tourism, Channel View Publications, Bristol, 125-142, 2012

[11] V. Eichhorn, D. Buhalis. D. A Key Objective for the Tourism Industry. In Buhalis D., Darcy S. (eds.), Accessible Tourism. Concept and Issues. Aspects of Tourism Series. Channel View Publications. Bristol, 46-61, 2011.

[12] A. Bryman. Chapter 25 - Mixed Methods Research: Combining Quantitative and Qualitative Research. In Social Research Methods, 3rd Edition ( $1^{\text {st }}$ edition 2001). Oxford, 603-626, 2008. Social Research Methods, 3rd Edition (1 $1^{\text {st }}$ edition 2001). Oxford, 603-626, 2008.

[13] M. Brito. Informação Turística - A Arte do Guia Interprete: Entre a cultura do Turista e o Destino. Chiado Editora, Lisboa, 2013.

[14] I. Ambrose. Developing a European Map for Accessible Tourism Policy. In Turismo Acessível. Revista Turismo e Desenvolvimento, (11), Aveiro, 47-57, 2009. 